\title{
Consideration of Immediate and Future Consequences in Accepting and Responding to Anthropogenic Climate Change
}

\author{
Victor Corral-Verdugo ${ }^{1}$, Joaquin Caso-Niebla ${ }^{2}$, Cesar Tapia-Fonllem ${ }^{1}$, Martha Frías-Armenta1 \\ ${ }^{1}$ University of Sonora, Hermosillo, Mexico \\ ${ }^{2}$ Autonomous University of Baja California, Ensenada, Mexico \\ Email: *victorcorral@sociales.uson.m
}

How to cite this paper: Corral-Verdugo, V., Caso-Niebla, J., Tapia-Fonllem, C., \& FríasArmenta, M. (2017). Consideration of Immediate and Future Consequences in Accepting and Responding to Anthropogenic Climate Change. Psychology, 8, 1519-1531. https://doi.org/10.4236/psych.2017.810101

Received: June 30, 2017

Accepted: August 7, 2017

Published: August 10, 2017

Copyright () 2017 by authors and Scientific Research Publishing Inc. This work is licensed under the Creative Commons Attribution International License (CC BY 4.0).

http://creativecommons.org/licenses/by/4.0/

\section{(c) (i) Open Access}

\begin{abstract}
Decreasing greenhouse gas emissions (climate change mitigation) is one of the most important types of pro-environmental behavior. Greenhouse gases have been repeatedly cited as a leading cause of climate change (CC). However, before engaging in $\mathrm{CC}$ mitigation behaviors, individuals must accept the reality of CC. Few studies addressing the influence of individual time perspective on climate change mitigation have been found. No study investigating the relationship between time perspectives and acceptance of the reality of CC exists. This study was aimed at filling that research gap. The study examines the impact of consideration of immediate and distant consequences of behavior on individual acceptance of the reality of CC and commitment to engage in CC mitigation behaviors. Two-hundred-and-forty-five undergraduate students responded to an instrument investigating those variables. A structural-equation model revealed that consideration of distant consequences affects acceptance of CC, but considering immediate consequences do not influence that acceptance. Accepting that $\mathrm{CC}$ is real affects the commitment to act pro-environmentally, which in turn influences CC mitigation commitment. Consideration of distant consequences also positively affects willingness to engage in CC mitigation; yet, consideration of immediate consequences produced no effect on that commitment.
\end{abstract}

\section{Keywords}

Climate Change, Mitigation, Immediate, Future, Consequences

\section{Introduction}

\subsection{Climate Change and Mitigation Behavior}

Climate change (CC) is probably the most serious and pressing environmental 
problem humankind has ever faced. Although climate variability is a natural phenomenon that has manifested itself through eons Earth's history, the current CC is peculiar because it is caused by humans, a fact accepted by more than $97 \%$ of the scientific community (Cook, Nuccitelli, Green et al., 2013). The emission of greenhouse gases-carbon dioxide, methane and nitrous oxide-from people's daily activities (use of fossil fuels, changes in soil use, intensive agricultural patterns) is responsible for the elevation of average temperature and changes in climate variability (Crowley, 2000).

A number of pro-environmental behaviors inhibit the emission of greenhouse gases. These behaviors include walking or biking instead of driving a car, decreasing meat eating, eating fresh seasonable and local vegetables, using natural fertilizers in agriculture, energy and water conservation, avoiding air travel, and reducing consumption of products, among many others (Gatersleben, Steg, \& Vlek, 2002; Brüger, Morton, \& Dessai, 2015). People who engage in those behaviors usually make a conscious commitment to face the consequences of climate change (Whitmarsh, 2009; Broomell, Budescu, \& Por, 2015). Thus, the study of this kind of commitment is important in determining factors that promote CC mitigation behavior. The study of actions committed specifically to fight climate change is particularly relevant, because a difference exists between actions intentionally directed to mitigate climate change and actions driven by other types of intentions (such as economic reasons, moral imperatives, habits, etc.); these differences may be crucial in fighting climate change (Whitmarsh, 2009).

Yet, before an individual develops a commitment to engage in CC mitigation behaviors, she or he must accept that climate change is actually happening and humans are causing it (Howe \& Leiserowitz, 2013). Although the scientific knowledge and certainty regarding CC have solidified in recent decades, public understanding of climate change has not improved. The problem is that as more scientific knowledge is achieved, the more polarized the popular perceptions in regard to this phenomenon become (Weber \& Stern, 2011). As a consequence of this discrepancy many people deny that CC is occurring; therefore, they are not able to face and solve it. Climate change denial may be total or take the form of skepticism or uncertainty (Whitmarsh, 2009).

\subsection{Time Perspective and Climate Change}

Once acceptance of CC reality and the commitment to inhibit its effects are established as preconditions for climate change mitigation, researchers need to determine psychological factors that facilitate CC acceptance and commitment to engage in CC mitigation behaviors. Time perspective (i.e., drawing on past memories, experience the present or looking forward to future) is one of those factors.

The pertinent literature in the environmental psychology field reveals the importance of time perspective in influencing people's decision to engage in environmentally-protective behaviors (Joireman, Van Lange, \& Van Vugt, 2004; Mil- 
font \& Gouveia, 2006; Pahl \& Bauer, 2013). According to the literature, people who are more future-oriented tend to engage in more sustainable actions than those who reveal a propensity towards the past, the present or the immediate future (Corral-Verdugo, Fraijo-Sing, \& Pinheiro, 2006; Pinheiro \& Corral-Verdugo, 2010; Milfont, Wilson, \& Diniz, 2012). Environmental problems involve not only a conflict between personal and social costs and benefits but also a conflict between short-term and long-term interests (Cameron, Brown, \& Chapman, 1998; Milfont \& Gouveia, 2006). As such the study of this divergent time perspective is relevant in the psychology of sustainability field. However, most of the study on the relationship between time perspective and pro-environmental behaviors has focused on the influence that future orientation has on people's determination to protect the environment.

With this emphasis on the effect of future perspective on environmental concern it is not surprising that researchers choose to develop and use measures of future propensity in their studies. One of those measures is the Consideration of Future Consequences scale (CFCS). Developed by Strathman, Gleicher, Boninger, \& Edwards (1994), the CFCS has been traditionally assumed as a unidimensional scale assessing a factor that ranges from low $\mathrm{CFC}$ of immediate behavior to high CFC of immediate behavior (Arnocky, Milfont, \& Nicol, 2014). However, multiple studies have found a bi-factorial structure of the CFCS, which seems to reveal a dimension tackling the consideration of short-term or immediate consequences of behavior, and another that addresses the consideration of long-term or distant consequences (Adams, 2012; Arnocky et al., 2014; Charlton, Gossett, \& Charlton, 2011; Toepoel, 2010). If this bi-dimensional structure in the CFCS continues to be confirmed, the instrument would be helpful in investigating the conflict between short-term and long-term interests in environmental matters, adding a temporal dimension other than the future orientation into the investigation of CC determinants. More than purely confirming the bi-dimensional structure of the CFCS throughout factor analysis, the idea is to examine the instrument's “ability to differentially predict relevant outcomes" (Joireman, Shaffer, Balliet, \& Strathman, 2012: p. 1278). Human acceptance and response to climate change are two of those relevant outcomes.

One study (Joireman, Kees, \& Sprott, 2010) showed that compulsive buying tendencies (highly associated to greenhouse emissions) positively correlated with immediate consideration of consequences, while the correlation with future consequences was nonsignificant. Another study (Khachatryan, Joireman, \& Casavant, 2013) demonstrated that preference for biofuels (corn- and cellulose-based ethanol) was negatively related to consideration of immediate consequences and positively associated with consideration of future consequences.

Arnocky et al. (2014: p. 556), using the CFCS, distinguished between CFC-Immediate and CFC-Future and found that low scores on the CFC-Immediate predicted environmental concern, with nonsignificant effects for CFC-Future. They also found that "the associations between future time perspective and sustainable 
behaviors are driven by reduced immediate concerns". These findings suggest that the immediate consideration of consequences is predictive of greenhouse-gas emission behaviors while the consideration of distant consequences could be associated to the commitment to mitigate climate change. No studies investigating the association between considerations of consequences of behavior and acceptance of CC occurrence have been found.

Therefore, the purpose of this study was to test a model of inter-relations between consideration of immediate and distant consequences of behavior, acceptance of the reality of climate change, and the commitment to engage in pro-environmental and CC mitigation behaviors.

\section{Methods}

\subsection{Participants}

Two-hundred and forty-five undergraduate students (143 females, 102 males) attending a public Mexican university participated in this study. They responded to a pencil and paper instrument. Their average age was 20.4 years $(S D=1.7)$ and their socio-economic status was mostly middle-class.

\subsection{Instrument}

Four scales in Likert-type response format were used. One scale investigated levels of acceptance of climate change, indicating how much the respondent agreed $(1=$ total disagreement... $5=$ total agreement $)$ with 5 items stating that climate change is real, important and caused by humans. One more scale assessed commitment to engage in actions to mitigate climate change-such as reducing use of car, conserving water at home, buying locally produced food, turning off electronic devices, etc.-with 12 items using a 5-option responseformat $(1=$ not likely at all... $5=$ very likely). Commitment to engage in general pro-environmental behaviors - such as giving money to environmental groups, voting for pro-environmental candidates, boycotting companies that are not environmentally friendly, etc.-was measured using 12 items in the same 1 - 5 response format. These three scales were developed by Bain et al. (2016) for an international study on human responses to climate change. The Consideration of Future Consequences Scale (Strathman et al., 1994) was the fourth used instrument. It includes 14 items revealing both consideration of immediate consequences ("My behavior is only influenced by the immediate outcomes", "I only act to satisfy immediate concerns") and consideration of distant consequences ("I consider how things might be in the future", "My behavior is generally influenced by future consequences") using a 5 -point response format $(1=$ not at all like me.. 5 = very much like me). In addition, participants were asked to manifest with a "yes" or "no" response whether or not they accepted that climate change is real and humans are causing it. All scales were administered in Spanish in the same order to all participants. The Spanish translation of those instruments was produced using the back-translation method. 


\subsection{Procedure}

The instrument was administered in the participants' classroom. They were debriefed on the aims of the study and their informed consent to participate was obtained. None refused to collaborate with the study. The administration of the scales took about fifteen minutes.

\subsection{Data Analysis}

Univariate statistics (means, standard deviations, maximum and minimum values), as well as one indicator of internal consistency for the scales (Cronbach's alpha) were computed. An exploratory factor analysis was performed on the CFC scale, in order to verify its two-dimensional structure. A matrix of correlation between the analyzed variables-acceptance of CC, commitment to mitigate CC, commitment to pro-environmental behavior, immediate consideration of consequences, distant consideration of consequences-was also obtained. Parcels were computed from the items of every scale (the exception was acceptance of CC, wherein all the items were considered without parceling), so that they could be used as indicators for the factors in a structural model, utilizing the EQS statistical package (Bentler, 2006). This structural model specified that the two considerations of future consequences of behavior (immediate and distant) would affect both acceptance of CC and the commitment to engage in actions that mitigate climate change. The model also specified that consideration of distant consequences positively influences acceptance of CC, while consideration of immediate consequences exerts a negative influence on that acceptance. A positive influence of consideration of distant consequences and a negative effect of immediate consequences on pro-environmental commitment were also specified. Moreover, according to the model, acceptance of CC influences both commitment to pro-environmental behaviors and to CC mitigating behaviors. A significant association between both types of commitment was expected.

\section{Results}

Table 1 shows the frequency and percentages of participants that accepted that climate change is real and humans are causing it (according to responses to the Acceptance of Climate Change Scale). Slightly more than eighty-four percent of these participants believed in the reality of CC while almost thirteen percent either denied the reality of CC or were skeptic of its human causes.

An exploratory factor analysis (principal components and Varimax rotation) of the CFC scale revealed two clearly distinguishable dimensions of the scale with items saliently and significantly loading on either a factor of consideration of immediate consequences, or a factor of consideration of distant consequences. These two factors explained $45.6 \%$ of the variance in the participants' responses to the CFC instrument.

Tables 2-4 show that the levels of internal consistency of all the used the scales are acceptable; Cronbach's alphas values resulted .70 or higher for every 
Table 1. Respondents that believe climate change is real and humans are causing it.

\begin{tabular}{lcc}
\hline & Frequency & Percentage \\
\hline $\begin{array}{l}\text { 1) I think climate change is occurring and human activities } \\
\text { are having significant effects }\end{array}$ & 211 & 84.4 \\
$\begin{array}{l}\text { 2) I think climate change is occurring but human activities } \\
\text { are not having significant effects }\end{array}$ & 32 & 12.8 \\
3) I do not believe climate change is occurring & 2 & .8 \\
\hline
\end{tabular}

Table 2. Reliability and univariate statistics of climate-change acceptance scale.

\begin{tabular}{lccccc}
\hline \multicolumn{1}{c}{ SCALE/Items } & Mean & SD & Min & Max & Alpha \\
\hline $\begin{array}{l}\text { CLIMATE CHANGE } \\
\text { ACCEPTANCE .70 }\end{array}$ & 4.27 & .68 & 1 & 5 & .70 \\
Climate change is real & 4.58 & .76 & & & \\
$\begin{array}{l}\text { Humans significantly affect climate } \\
\text { change }\end{array}$ & 4.28 & .92 & & \\
$\begin{array}{l}\text { Coping with CC is a very important } \\
\text { problem } 4.01 .88\end{array}$ & 4.01 & .88 & & \\
$\begin{array}{l}\text { Climate change is caused by human } \\
\text { beings } 3.861 .0\end{array}$ & 3.86 & 1.0 & & \\
$\begin{array}{l}\text { Climate change is not real (reversed) } \\
4.62 .76\end{array}$ & 4.62 & .76 & & \\
\hline
\end{tabular}

assessed dimension. The univariate statistics revealed high levels of climate change acceptance among the respondents (mean $=4.27, \mathrm{SD}=.68$ ); participants also produced a moderately high mean $(3.82, \mathrm{SD}=1.43)$ in their report of proenvironmental commitment, and a higher commitment to engage in actions that mitigate climate change (mean $=4.18, \mathrm{SD}=1.06)$. The level of consideration of distant consequences of behavior was significantly higher (mean $=3.53, \mathrm{SD}=$ 1.04) than the one produced in regard to consideration of immediate consequences (mean $=2.41, \mathrm{SD}=1.08 ; t=15.5, p<.0001$ ).

Table 5 shows the matrix of interrelations among the studied variables. All of these variables correlated positively and significantly with each other, except the consideration of immediate consequences, which demonstrated no significant correlation to any of the remaining variables. This matrix suggests that consideration of distant consequences, acceptance of CC reality, pro-environmental commitment, and willingness to engage in CC mitigating behaviors go together in responding to climate change. Therefore, the subsequently performed structural-equation model used this evidence in its specification phase.

The measurement model of the structural equation analysis (see Figure 1) produced high and significant $(p<.05)$ factor loadings between every factor and their corresponding indictors. These results seem to evidence convergent validity for the used measures. The value of the structural coefficients between factors is lower than the value of those factor loadings, which indicates discriminant 
Table 3. Reliability and univariate statistics of pro-environmental commitment and climate change mitigation commitment scales.

\begin{tabular}{|c|c|c|c|c|c|}
\hline SCALE/Items & Mean & $\mathrm{SD}$ & Min & $\operatorname{Max}$ & Alpha \\
\hline PROENVIRONMENTAL COMMITMENT & 3.82 & 1.43 & 1 & 5 & .84 \\
\hline Give money to an environmental group & 3.75 & 1.64 & & & \\
\hline Read environmental groups' publications & 4.19 & 1.07 & & & \\
\hline $\begin{array}{l}\text { Sign a petition in support of protecting the } \\
\text { environment }\end{array}$ & 4.28 & 1.08 & & & \\
\hline $\begin{array}{l}\text { Call government official to support } \\
\text { environmental protection }\end{array}$ & 3.68 & 1.57 & & & \\
\hline Vote for pro-environmental candidate & 4.05 & 1.26 & & & \\
\hline $\begin{array}{l}\text { Write to newspaper in support of } \\
\text { environmental protection }\end{array}$ & 3.59 & 1.59 & & & \\
\hline $\begin{array}{l}\text { Boycott companies that are not } \\
\text { environmentally friendly }\end{array}$ & 3.64 & 1.77 & & & \\
\hline $\begin{array}{l}\text { Join or renew membership of an } \\
\text { environmental group }\end{array}$ & 3.71 & 1.47 & & & \\
\hline Volunteer to help a pro-environmental group & 3.96 & 1.21 & & & \\
\hline $\begin{array}{l}\text { Attend public manifestations to protect the } \\
\text { environment }\end{array}$ & 3.50 & 1.61 & & & \\
\hline $\begin{array}{l}\text { Upload pro-environmental messages in social } \\
\text { networks }\end{array}$ & 3.50 & 1.61 & & & \\
\hline $\begin{array}{l}\text { Talk to friends and family about } \\
\text { environmental policies }\end{array}$ & 3.98 & 1.30 & & & \\
\hline $\begin{array}{l}\text { CLIMATE CHANGE MITIGATION } \\
\text { COMMITMENT }\end{array}$ & 4.18 & 1.06 & 1 & 5 & .88 \\
\hline Install energy-saving devices at home & 4.50 & 1.00 & & & \\
\hline Buy environmentally-friendly products & 4.32 & .93 & & & \\
\hline Conserve water at home & 4.48 & .85 & & & \\
\hline Reduce use of air conditioning or heating & 3.86 & 1.26 & & & \\
\hline Reduce use of car & 3.83 & 1.33 & & & \\
\hline Turn off lights and appliances when not in use & 4.66 & .79 & & & \\
\hline Avoid or reduce meat consumption & 3.76 & 1.26 & & & \\
\hline Recycle products & 4.17 & .97 & & & \\
\hline $\begin{array}{l}\text { Turn off electronic devices instead of } \\
\text { pausing them }\end{array}$ & 4.40 & .92 & & & \\
\hline Buy locally produced food & 4.10 & 1.10 & & & \\
\hline Share car to travel or carpooling & 4.08 & 1.21 & & & \\
\hline Purchase items with minimal packaging & 4.01 & 1.21 & & & \\
\hline
\end{tabular}

validity (Corral-Verdugo \& Figueredo, 1999). Most of the hypothesized relations between factors were confirmed, according to the results of the tested structural 
Table 4. Reliability and univariate statistics of consideration of immediate and distant consequences scales.

\begin{tabular}{cccccc}
\hline SCALE/Items & Mean & SD & Min & Max & Alpha \\
\hline CONSIDERATION OF DISTANT CONSEQUENCES & 3.53 & 1.04 & 1 & 5 & .73
\end{tabular}

I consider how things might be in the future, and try to influence those things with my day to day behavior.

Often I engage in a particular behavior in order to achieve outcomes that may not result for many years.

\begin{tabular}{|c|c|c|c|c|}
\hline 3.88 & .90 & & & \\
\hline 3.28 & 1.05 & & & \\
\hline 3.08 & 1.12 & & & \\
\hline 3.16 & 1.11 & & & \\
\hline 3.81 & 1.01 & & & \\
\hline 3.40 & 1.05 & & & \\
\hline 4.20 & 0.94 & & & \\
\hline 3.45 & 1.13 & & & \\
\hline 2.41 & 1.08 & 1 & 5 & .83 \\
\hline 2.44 & 1.09 & & & \\
\hline 2.58 & 1.09 & & & \\
\hline 2.21 & 1.02 & & & \\
\hline 2.18 & 1.06 & & & \\
\hline 2.39 & 1.10 & & & \\
\hline 2.69 & 1.10 & & & \\
\hline
\end{tabular}

My convenience is a big factor in the decisions I make or the actions I take.

I am willing to sacrifice my immediate happiness or "well-being in order to achieve future outcomes".

I think it is important to take warnings about negative outcomes seriously even if the negative outcome will not occur for many years.

I think it is more important to perform a behavior with important distant consequences than a behavior with less-important immediate consequences.

When I make a decision, I think about how it might affect me in the future.

My behavior is generally influenced by future consequences.

\section{CONSIDERATION OF IMMEDIATE CONSEQUENCES}

I only act to satisfy immediate concerns, figuring the future will take care of itself.

My behavior is only influenced by the immediate (i.e., a matter of days or weeks) outcomes of my actions.

I generally ignore warnings about possible future problems because I think the problems will be resolved before they reach crisis level.

I think that sacrificing now is usually unnecessary since future outcomes can be dealt with at a later time.

I only act to satisfy immediate concerns, figuring that I will take care of future problems that may occur at a later date.

Since my day to day work has specific outcomes, it is more important to me than behavior that has distant outcomes.

model. The consideration of distant consequences affected the level of acceptance of the reality of CC (structural coefficient $=.37 ; p<.05$ ), but considering immediate consequences did not produce such effect. Accepting that climate change is real influenced the commitment to act pro-environmentally (structural coefficient $=.18 ; p<.05)$, which, in turn, influenced CC mitigation commitment (structural coefficient $=.55 ; p<.05)$. Consideration of distant consequences also positively affected both the willingness to engage in CC mitigation (structural 
Table 5. Correlation matrix of studied variables.

\begin{tabular}{ccccc}
\hline & CCAccept & Proenv Comm & Mitig Commit & Distant Cons. \\
\hline CCAccept & & & & \\
Proenv Comm & $.18^{\star}$ & & & \\
Mitig Comm & $.17^{\star}$ & $.49^{\star}$ & $.24^{\star}$ & .01 \\
Distant Cons. & $.28^{\star}$ & $.18^{\star}$ & .04 & .02 \\
Immediate C. & -.10 & .02 & & \\
\hline
\end{tabular}

${ }^{*}$ Significant at $p<.01$.

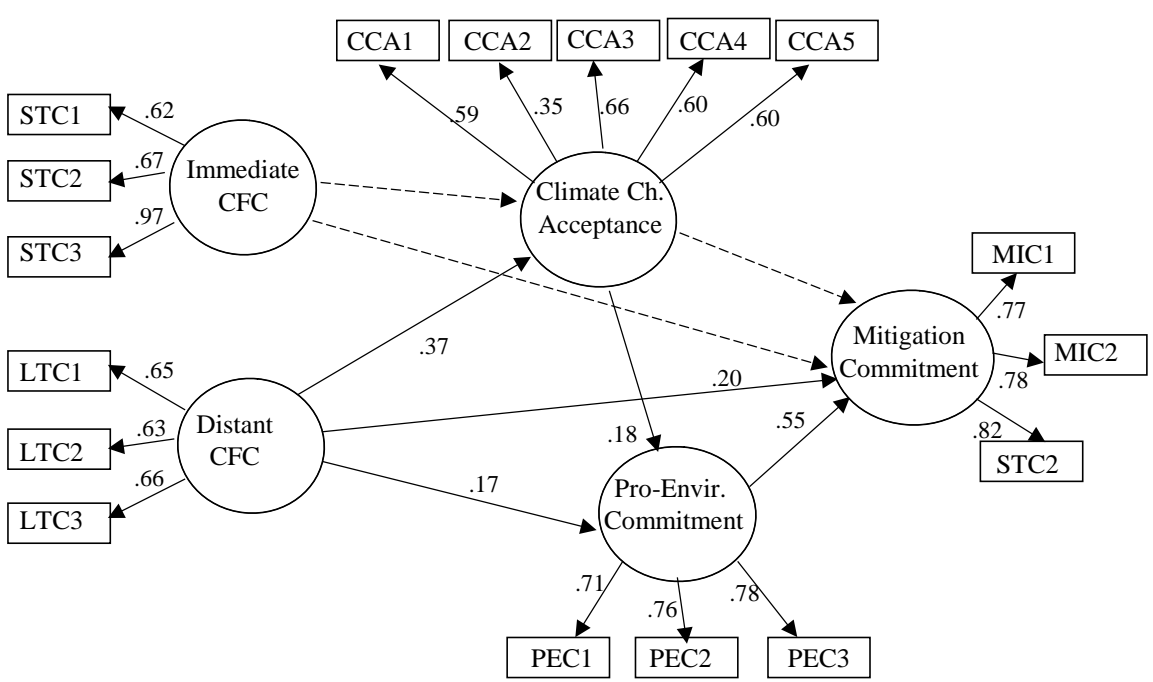

Figure 1. Model of interrelations between immediate and distant consideration of future consequences, acceptance of climate change, pro-environmental commitment and mitigation commitment, All factor loadings and the structural coefficient are significant ( $p$ $<.05)$, except the ones indicated by dotted-line arrows. Goodness of fit: Chi-squared = $185(110 d f), p<.001 ; B B N N F I=.92, C F I=.94 ; R M S E A=.05$. Mitigation Commitment $R^{2}=.41$.

coefficient $=.20 ; p<.05$ ) and the commitment to act pro-environmentally (structural coefficient $=.17 ; p<.05)$; yet, consideration of immediate consequences produced no effect on either commitment.

Goodness of fit indicators of this model seems to evidence its adequacy. Although the chi-square value $\left(X^{2}=185,110 d f\right)$ associated to this model was significant $(p<.0001)$, the practical indices $B N N F I(.92)$ and $C F I(.94)$ as well as RMSEA (.05) values support the pertinence of this model of interrelations.

\section{Discussion}

As previous studies and our results show, humans often attend to immediate consequences of their behavior to the detriment of consideration of their longterm consequences. Clearly, greenhouse-gas emitting behaviors produce distant consequences (climate change) and our temporal myopia (i.e., seeing only the short-term) prevents us from anticipating the consequences of our actions in the 
distant future. Behaviors such as moderate consumption of products (Strathman et al., 1994), the support to public transportation systems (Joireman et al., 2004), and recycling (Ebreo \& Vining, 2001) are inhibited in individuals who do not perceive the future consequences of their behavior. Although our sample of participants consisted of people with an above average level of education, we found variability in levels of consideration of immediate and future consequences, and commitment to protect the environment; a variability that was sufficient enough to reveal significant associations between those variables.

Our study not only found that time orientation is a significant factor influencing the commitment to act inhibiting climate change; it also indicated that such orientation influences the acceptance of $\mathrm{CC}$ as a phenomenon that is happening and is resulting from human causes. People who were prone to anticipate the distant consequences of their behavior were more likely to accept the reality of anthropogenic CC; conversely, those who focused on immediate consequences of behaviors did not easily accept the CC reality. It is likely that their bias toward immediate consequences prevented their acceptance of such climatic phenomenon because it is difficult to perceive a connection between short-term consequences of own behavior and more distant effects, especially when the immediate consequences are not similar to the ones that supposedly will occur. In the case of climate change the problem is that its more dangerous manifestations have not fully developed.

This differential influence of consideration of immediate and distant consequences also applies to the commitment to mitigate $\mathrm{CC}$ and engage in general pro-environmental behaviors. The distant consequences consideration was significantly associated to such commitments. However, no association between consideration of immediate consequences was found on either commitment. These findings replicate previous results (Arnocky et al., 2014; Joireman et al., 2010; Khachatryan et al., 2013) showing that consideration of future consequences correlates positively with environmental concern; yet in those studies consideration of immediate consequences also (negatively) correlated with such concern. Our study, however, found consideration of short-term consequences was not significantly associated with any other examined factor. This discrepancy deserves further study. Although it is not very clear why these findings did not result as expected, we speculate that since most of the climate change consequences are yet to come, a person with high levels of consideration of future consequences is more prone to accept the occurrence of CC. As a consequence, he or she is more determined to engage in CC mitigating behaviors. Conversely, someone more inclined to the consideration of immediate consequences is indifferent in accepting $\mathrm{CC}$ as a real phenomenon and in engaging in CC mitigating behaviors.

Our results also contribute to the analysis of the components of social dilemmas, as seen in the case of climate change and other environmental and social problems. A number of authors have noticed that, very often in these problems, individual self-interest is also short-term interest and this egoistic consideration 
of immediate consequences is at odds with long-term collective interest (Joireman et al., 2004; Milfont \& Gouveia, 2006; Nordlund \& Garvill, 2003). Since it is clear that this situation involves a social conflict (egoistic vs. collective interest) and a temporal conflict (immediate vs. future interest), those authors have referred to it as the "expanded definition of social dilemmas" implying that, in studying social dilemmas, a temporal consideration is as important as the consideration of individual vs. collective benefits (as the traditional approach to social dilemmas conceives this situation). Our study results suggest that long-term interest not only influences collective interest but also affects the levels of awareness concerning a situation that jeopardizes such collective interest (i.e., climate stability).

If future consideration of consequences is important in influencing CC acceptance and commitment to engage in CC mitigation behaviors, what can be done to promote a future orientation among people? Although there is no definitive answer to such question, some aspects addressing it have been provided in previous studies. For instance, the use of prospect-concept priming tasks activates future thinking, and results in increased environmental concern. These tasks prime future orientation by asking people to envision what their everyday life circumstances might be in years in the future (Arnocky et al., 2014). One more possibility is the implementation of educational programs that include "the acquisition of time-administration skills, the training in planning tasks, in combination with the development of social norms and values" (Corral-Verdugo et al., 2006: p. 146). According to the authors issuing the latter recommendation, it could be a fruitful strategy in developing a future-oriented perspective and, subsequently, a pro-environmental commitment. More strategies should be implemented and tested in trying to promote future orientation among people.

Concern for immediate consideration of consequences may be a trait selected by evolutionary pressures (Rickles, 2016): paying attention to the immediate was valuable in ancestral times because it allowed individuals to focus on the most urgent and important everyday problems, such as surviving and obtaining mates. Indeed, this "enhancing-short-term-considerations" trait continues being valuable in our daily adaptation to the environment. Yet, in some cases (such as facing CC) the activation of a more-distant-consideration of consequences proves useful. Humans are also equipped to anticipate the future, and we can use this feature of our species' nature to fight the dangerous consequences of climate change.

\section{Acknowledgements}

The authors thank the Mexican Council of Science and Technology for its support in the conduction of this study.

\section{References}

Adams, J. (2012). Consideration of Immediate and Future Consequences, Smoking Status, and Body Mass Index. Health Psychology, 31, 260-263. 
https://doi.org/10.1037/a0025790

Arnocky, S., Milfont, T., \& Nicol, J. (2014). Time Perspective and Sustainable Behavior. Environment \& Behavior, 46, 556-582. https://doi.org/10.1177/0013916512474987

Bain, P., Milfont, T., Kashima, Y., Bilewicz, M., Doron, G., Garðarsdóttir, R., Gouveia, V., Guan, Y., Johansson, L., Pasquali, C., Corral-Verdugo, V. et al. (2016). Co-Benefits of Addressing Climate Change Can Motivate Action around the World. Nature Climate Change, 6, 154-156. https://doi.org/10.1038/nclimate2990

Bentler, P.M. (2006). EQS, Structural Equations Program Manual. Encino, CA: Multivariate Software Inc.

Broomell, S., Budescu, D., \& Por, H. (2015). Personal Experience with Climate Change Predicts Intentions to Act. Global Environmental Change, 32, 67-73. https://doi.org/10.1016/j.gloenvcha.2015.03.001

Brüger, A., Morton, T., \& Dessai, S. (2015). Hand in Hand: Public Endorsement of Climate Change Mitigation and Adaptation. Plos One, 10, e 0124843.

https://doi.org/10.1371/journal.pone.0124843

Cameron, L. D., Brown, P. M., \& Chapman, J. G. (1998). Social Value Orientations and Decisions to Take Proenvironmental Action. Journal of Applied Social Psychology, 28, 675-697. https://doi.org/10.1111/j.1559-1816.1998.tb01726.x

Charlton, S. R., Gossett, B. D., \& Charlton, V. A. (2011). Beyond the Shadow of a Trait: Understanding Discounting through Item-Level Analysis of Personality Scales. Psychological Record, 61, 583-598. https://doi.org/10.1007/BF03395778

Cook, J., Nuccitelli, D., \& Green, S. et al. (2013). Quantifying the Consensus on Anthropogenic Global Warming in the Scientific Literature. Environmental Research Letters, 8, 024024. https://doi.org/10.1088/1748-9326/8/2/024024

Corral-Verdugo, V., \& Figueredo, A. J. (1999). Convergent and Divergent Validity of Three Measures of Conservation Behavior: The Multitrait-Multimethod Approach. Environment \& Behavior, 31, 805-820. https://doi.org/10.1177/00139169921972353

Corral-Verdugo, V., Fraijo-Sing, B., \& Pinheiro, J. Q. (2006). Sustainable Behavior and Time Perspective: Present, Past, and Future Orientations and Their Relationship with Water Conservation Behavior. Interamerican Journal of Psychology, 40, 139-147.

Crowley, T. J. (2000). Causes of Climate Change over the Past 1000 Years. Science, 289, 270-277. https://doi.org/10.1126/science.289.5477.270

Ebreo, A., \& Vining, J. (2001). How Similar Are Recycling and Waste Reduction? Future Orientation and Reasons for Reducing Waste as Predictors of Self-Reported Behavior. Environment \& Behavior, 33, 424-448. https://doi.org/10.1177/00139160121973061

Gatersleben, B., Steg, L., \& Vlek, C. (2002). Measurement and Determinants of Environmentally Significant Consumer Behavior. Environment and Behavior, 34, 335-362. https://doi.org/10.1177/0013916502034003004

Howe, P. D., \& Leiserowitz, A. R. (2013). Who Remembers a Hot Summer or a Cold Winter? The Asymmetric Effect of Beliefs about Global Warming on Perceptions of Local Seasonal Climate Conditions in the U.S. Global Environmental Change, 23, 14881500. https://doi.org/10.1016/j.gloenvcha.2013.09.014

Joireman, J., Kees, J., \& Sprott, D. (2010). Concern with Immediate Consequences Magnifies the Impact of Compulsive Buying Tendencies on College Students' Credit Card Debt. Journal of Consumer Affairs, 44, 155-178. 
https://doi.org/10.1111/j.1745-6606.2010.01161.x

Joireman, J., Shaffer, M., Balliet, D., \& Strathman, A. (2012). Promotion Orientation Explains Why Future Oriented People Exercise and Eat Healthy: Evidence from the TwoFactor Consideration of Future Consequences 14 Scale. Personality and Social Psychology Bulletin, 38, 1272-1287. https://doi.org/10.1177/0146167212449362

Joireman, J., Van Lange, P. A. M., \& Van Vugt, M. (2004). Who Cares about the Environmental Impact of Cars? Those with an Eye toward the Future. Environment \& Behavior, 36, 187-206. https://doi.org/10.1177/0013916503251476

Khachatryan, H., Joireman, J., \& Casavant, K. (2013). Relating Values and Consideration of Future and Immediate Consequences to Consumer Preference for Biofuels: A ThreeDimensional Social Dilemma Analysis. Journal of Environmental Psychology, 34, 97 108. https://doi.org/10.1016/j.jenvp.2013.01.001

Milfont, T. L., \& Gouveia, V. V. (2006). Time Perspective and Values: An Exploratory Study of Their Relations to Environmental Attitudes. Journal of Environmental Psychology, 26, 72-82. https://doi.org/10.1016/j.jenvp.2006.03.001

Milfont, T. L., Wilson, J., \& Diniz, P. K. C. (2012). Time Perspective and Environmental Engagement: A Meta-Analysis. International Journal of Psychology, 47, 325-334. https://doi.org/10.1080/00207594.2011.647029

Nordlund, A. M., \& Garvill, J. (2003). Effects of Values, Problem Awareness, and Personal Norm on Willingness to Reduce Personal Car Use. Journal of Environmental Psychology, 23, 339-347. https://doi.org/10.1016/S0272-4944(03)00037-9

Pahl, S., \& Bauer, J. (2013). Overcoming the Distance: Perspective Taking with Future Humans Improves Environmental Engagement. Environment \& Behavior, 45, 155-169. https://doi.org/10.1177/0013916511417618

Pinheiro, J., \& Corral-Verdugo, V. (2010). Time Perspective and Sustainable Behavior. In V. Corral-Verdugo, C. García, \& M. Frías (Eds.), Psychological Approaches to Sustainability. New York: Nova Science Publishers.

Rickles, D. A. (2016). Participatory Future of Humanity. In A. Aguirre, B. Foster, \& Z. Merali (Eds.), How Should Humanity Steer for the Future (pp. 49-59)? New York: Springer. https://doi.org/10.1007/978-3-319-20717-9_6

Strathman, A., Gleicher, F., Boninger, D. S., \& Edwards, C. S. (1994). The Consideration of Future Consequences: Weighing Immediate and Distant Outcomes of Behavior. Journal of Personality and Social Psychology, 66, 742-752.

https://doi.org/10.1037/0022-3514.66.4.742

Toepoel, V. (2010). Is Consideration of Future Consequences a Changeable Construct? Personality and Individual Differences, 48, 951-956. https://doi.org/10.1016/j.paid.2010.02.029

Weber, E. U., \& Stern, P. C. (2011). Public Understanding of Climate Change in the United States. American Psychologist, 66, 315-328.

https://doi.org/10.1037/a0023253

Whitmarsh, L. (2009). Behavioral Responses to Climate Change; Asymmetry of Intentions and Impacts. Journal of Environmental Psychology, 29, 13-23.

https://doi.org/10.1016/j.jenvp.2008.05.003 
Submit or recommend next manuscript to SCIRP and we will provide best service for you:

Accepting pre-submission inquiries through Email, Facebook, LinkedIn, Twitter, etc. A wide selection of journals (inclusive of 9 subjects, more than 200 journals)

Providing 24-hour high-quality service

User-friendly online submission system

Fair and swift peer-review system

Efficient typesetting and proofreading procedure

Display of the result of downloads and visits, as well as the number of cited articles Maximum dissemination of your research work

Submit your manuscript at: http://papersubmission.scirp.org/

Or contact psych@scirp.org 